\title{
On understanding inconsistent disciplinary behaviour in schools
}

\section{Authors: Anton Bekkerman \& Gregory Gilpin}

This is an Accepted Manuscript of an article published in Applied Economics Letters in 2015, available online: http://www.tandfonline.com/10.1080/13504851.2014.978065.

Bekkerman, Anton, and Gregory Gilpin. "On understanding inconsistent disciplinary behaviour in schools." Applied Economics Letters 22, no. 10 (2015): 772-776.

DOI: https://dx.doi.org/10.1080/13504851.2014.978065.

Made available through Montana State University's $\underline{\text { ScholarWorks }}$ 


\title{
On understanding inconsistent disciplinary behaviour in schools
}

\author{
Anton Bekkerman and Gregory Gilpin \\ Department of Agricultural Economics and Economics, Montana State \\ University, Bozeman, MT 59715-2920, USA
}

Inconsistent disciplinary administration across schools can inequitably impact students' education access opportunities by separating certain students from familiar learning environments, especially in misconduct cases that result in longer-term removal. We empirically estimate whether such inconsistencies are attributable to heterogeneity in student body demographic characteristics. The results indicate that a greater number of disciplines that remove students from school for an extended period of time are observed in schools with a higher proportion of black students, but no significant differential punishment effects are observed in schools with a higher Hispanic student population. Furthermore, results of decomposing the marginal effects into conditional and unconditional elasticities indicate that it is not the case that schools with predominantly white student bodies have the least severe punishments and schools with more minority students have the most severe punishments. Rather, schools with inconsistent disciplinary behaviour have a proportion of the inconsistency attributable to the race of the student body.

\section{Introduction}

Students unable to access their familiar education settings are more likely to experience diminished learning outcomes and are less likely to remain in school (Finn, 1989; Fitzpatrick et al., 2011). Bernburg and Krohn (2003) show that these effects are also evident when students are removed from schools due to misconduct discipline decisions, implying that schools' punishment practices can play a role in students' educational opportunities. Schools often have some discretion in their disciplinary decision-making process, which could lead to inequitable punishment outcomes if this process is influenced by factors that are not directly related to the evaluation of misconducts, such as student body demographic and socio-economic characteristics. Previous studies provide some evidence that school administrators' disciplinary decisions are affected by factors external to a misconduct case, including students' racial characteristics (e.g. see Welch and Payne, 2010; Kinsler, 2013). However, these studies evaluate inconsistencies in short-term punishment decisions, which have less impact on students' ability to attend school. Only limited research exists on potential inconsistencies in punishments that remove 
students for extended time periods, which can have significantly greater consequences on access to education.

This study investigates whether disciplinary inconsistencies across U.S. public high schools can be attributed to differences in the student body characteristics for misconducts that lead to long-term or permanent removal from the school. We find evidence that inconsistencies exist and that they, in part, can be attributed to the racial composition of the student body. Specifically, in schools with a higher proportion of black students, more misconducts are punished by long-term or permanent removal and more severe discipline is imposed in lieu of lesser punishments. Additionally, we decompose this finding to show that disciplinary variation attributable to student body demographics is only identified in schools where punishment inconsistencies exist, rather than in schools that simply have a higher proportion of minority students.

\section{Data and Empirical Specification}

Table 1 presents the variables used in this study, which represent combined data from the restricted-access versions of the 2003-2004, 2005-2006, 2007-2008 and 2009-2010 School Survey on Crime and Safety (SSOCS) for 3200 U.S. public high schools, the U.S. Census Bureau, the U.S. Bureau of Labor Statistics and the Federal Bureau of Investigation's Uniform Crime Reports. The SSOCS provides information about misconducts reported to school administrators, which were committed on school grounds, buses, or at school-sponsored events. These misconducts are categorized as one of four offenses: the possession or use of a nonfirearm weapon, illegal drugs, alcohol or being involved in a physical altercation with an intent to harm others. ${ }^{1}$ Due to the seriousness of these misconducts, punishments were either an expulsion or transfer of a student to an alternative school (permanent removal), a suspension exceeding five days (prolonged removal) or a short-term discipline (e.g. detention, suspension of fewer than 5 days, no punishment).
Table 2 provides preliminary insights about the heterogeneity in disciplinary decisions across schools with different student demographics. As expected, more serious misconducts are more severely punished, but across all offense categories, schools with significant black or Hispanic student bodies (i.e. schools where black or Hispanic student bodies are at least $25 \%$ ) expel or transfer students approximately $3-15$ percentage points more frequently than schools with a higher proportion of white students. Moreover, schools with a higher proportion of black and Hispanic students are more likely to use tougher punishments than schools with predominantly white student bodies, where suspensions are more prevalent than expulsions or transfers.

We separately model punishments across each of the four misconduct categories as the proportion of misconduct $j$ in school $i$ during school year $t$ that was assigned a discipline type $k, d_{i j t}^{k}=\left(\frac{\# \text { Disciplines }_{i j t}^{k}}{\# \text { Misconduct }_{i j t}}\right)$. This measure is modelled as a function of student body characteristics $\left(\boldsymbol{S} \boldsymbol{B}_{i t}\right)$, school-level and

Table 1. Variables in the empirical analysis

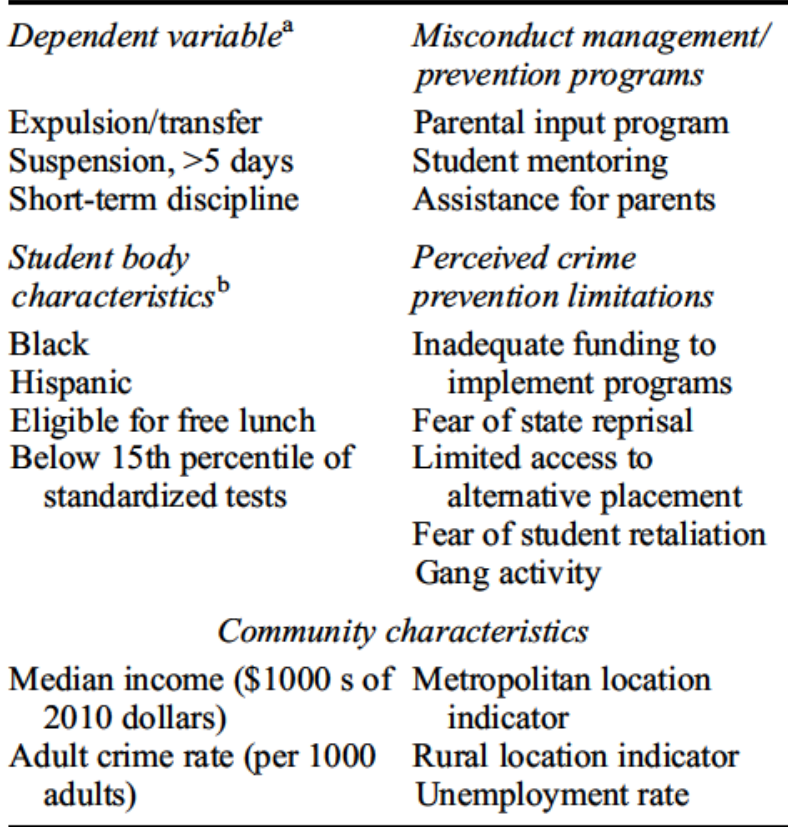

Notes: ${ }^{\mathrm{a}}$ Discipline per misconduct. ${ }^{\mathrm{b}}$ In per cent. Supplemental data provides detailed definitions for these variables.

\footnotetext{
${ }^{1}$ The SSOCS also includes information about firearm offenses. It is excluded from our analysis because the 1994 Gun-Free Schools Act mandates federal standardized punishments for these offenses, significantly reducing schools' discretion in disciplining these misconducts. These results are available upon request.
} 
Table 2. Descriptive statistics of disciplinary actions by student body demographics, in per cent

\begin{tabular}{lllll}
\hline & $\begin{array}{l}\text { Nonfirearm } \\
\text { weapon }\end{array}$ & $\begin{array}{l}\text { Illegal } \\
\text { drugs }\end{array}$ & Alcohol & $\begin{array}{c}\text { Physical } \\
\text { altercations }\end{array}$ \\
\hline $\begin{array}{l}\text { Expulsion/transfer } \\
\text { Black 58.1 }\end{array}$ & 51.0 & 30.2 & 21.9 \\
Hispanic & 53.2 & 42.0 & 26.5 & 15.6 \\
White 43.3 & 39.3 & 21.6 & 12.3 \\
Suspension, $>5$ days & & & \\
Black 31.9 & 37.9 & 52.6 & 51.4 \\
Hispanic & 30.4 & 30.8 & 32.8 & 32.4 \\
White 40.8 & 44.2 & 52.0 & 43.7 \\
Short-term discipline & & & \\
Black 9.9 & 11.2 & 17.2 & 26.7 \\
Hispanic & 16.4 & 27.1 & 40.7 & 52.0 \\
White 15.9 & 16.6 & 26.4 & 44.1 \\
\hline
\end{tabular}

Notes: 3200 nonalternative public high school observations. 'Black', 'Hispanic' and 'white' indicate the per cent of students disciplined by a particular punishment for one of the four misconducts in schools where the student body consists of at least $25 \%$ of black students, Hispanic students or white students, respectively. Discipline rankings among student body demographics did not change when the student body composition thresholds were altered between $10 \%$ and $50 \%$.

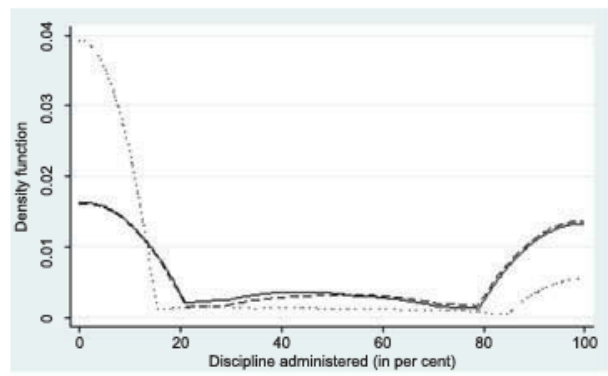

(a)

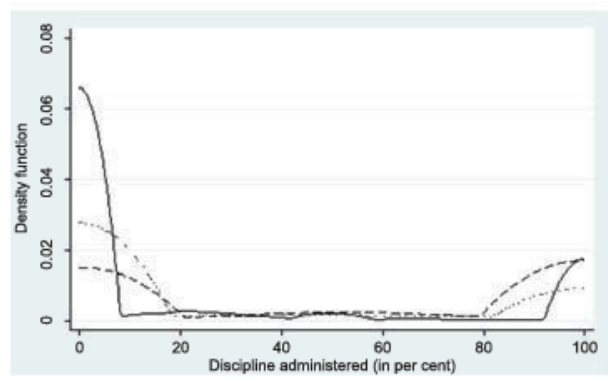

(c) community characteristics $\left(X_{i t}\right)$, and state and time fixed effects $\left(\delta_{s}\right.$ and $\left.\delta_{t}\right)$, which help capture statelevel school discipline mandates and other consistencies across schools and over the sample period, and idiosyncratic error term $\left(\varepsilon_{i j t}\right)$, that is,

$$
d_{i j t}^{k}=\beta_{0}+S B_{i t} \beta_{1}+X_{i t} \beta_{2}+\delta_{s}+\delta_{t}+\varepsilon_{i j t} .
$$

A school's use of a discipline $k$ is bounded between $0 \%$ and $100 \%$, where $0 \%$ indicates that discipline $k$ is never used and $100 \%$ indicates that all students committing a certain offense are identically disciplined. Figure 1 shows estimated probability density functions for discipline ratios across the four offense categories, which provide empirical evidence of substantial mass at the $0 \%$ and $100 \%$ bounds and likely represents administrators at a school $i$ consistently using the same discipline for certain offenses. Therefore, the observed proportion of discipline outcomes is characterized as

$$
\begin{aligned}
& d_{i j t}^{k}=0 \quad \text { if } d_{i j t}^{k^{*}} \leq 0 \\
& d_{i j t}^{k}=d_{i j t}^{k^{*}} \quad \text { if } 0<d_{i j t}^{k^{*}}<100 \\
& d_{i j t}^{k}=100 \quad \text { if } d_{i j t}^{k^{*}} \geq 100
\end{aligned}
$$

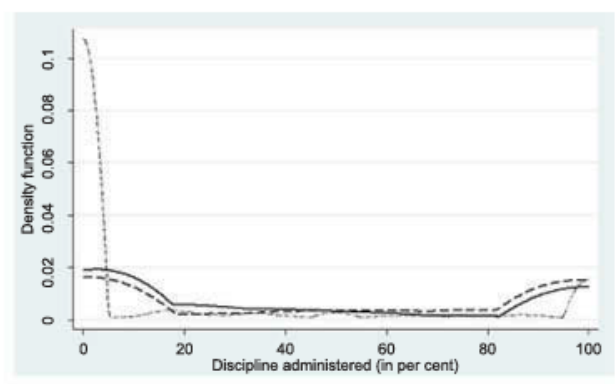

(b)

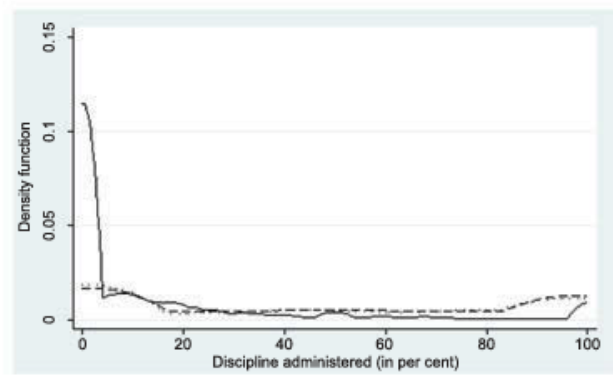

(d)

Expulsion/transfer

---- Suspension, $>5$ days

Short-term discipline

Fig. 1. Empirical probability density functions: (a) nonfirearm weapon, (b) illegal drugs, (c) alcohol and (d) physical altercations 
where the unobserved latent discipline outcome is $d_{i j t}^{k^{*}}$. A Tobit model with sampling weights provided by the SSOCS yields unbiased and consistent parameters estimates.

The Tobit model conveniently provides an opportunity to decompose marginal effects into conditional and unconditional elasticities between discipline outcomes and the variables of interest (McDonald and Moffitt, 1980), that is,

$$
\begin{gathered}
\varepsilon_{j}^{k}(C)=\frac{\partial E\left[0<d_{j}^{k}<1\right]}{\partial S B} \frac{S B}{E\left[0<d_{j}^{k}<1\right]} \\
\varepsilon_{j}^{k}(U C)=\frac{\partial E\left[d_{j}^{k}\right]}{\partial S B} \frac{S B}{E\left[d_{j}^{k}\right]}
\end{gathered}
$$

The two elasticities differ in how the estimate conditions over the discipline outcome space. The conditional elasticity (Equation 3a) characterizes the impacts on disciplinary actions in schools where within-school variation exists in discipline $k$ for misconduct $j$. The unconditional elasticity (Equation $3 \mathrm{~b}$ ) also includes information about schools that do not have within-school variation in a particular discipline.

\section{Results}

Table 3 presents estimates of the Tobit discipline model for the demographic variables of interest. The results show that discipline rates are affected by a school's student body racial composition. Discrepancies are manifest in increased expulsions and transfers in schools with a higher proportion of black students. Specifically, a $1 \%$ increase in the percentage of black students is positively correlated with average increases in the latent expulsion and transfer rates of $0.79,0.31$ and 0.31 percentage points for nonfirearm weapons, illegal drugs and physical altercations, respectively. Furthermore, more severe punishments appear to occur in lieu of lesser disciplines. For example, higher expulsion and transfer rates for nonfirearm and illegal drug
Table 3. Tobit discipline model estimates of latent marginal effects

\begin{tabular}{lllll}
\hline \multicolumn{1}{c}{$\begin{array}{l}\text { Nonfirearm } \\
\text { weapon }\end{array}$} & $\begin{array}{l}\text { Illegal } \\
\text { drugs }\end{array}$ & Alcohol $\begin{array}{l}\text { Physical } \\
\text { altercations }\end{array}$ \\
\hline Expulsion/transfer & & & \\
Black $0.792^{*}$ & $0.310^{*}$ & 0.847 & $0.308^{* * *}$ \\
Hispanic & 0.316 & -0.080 & -0.190 & -0.086 \\
Suspension, $>5$ days & & & \\
Black - $1.241^{* * *}$ & $-0.396^{*}$ & $0.906^{*}$ & $0.437^{* * *}$ \\
Hispanic -0.612 & -0.362 & -0.221 & -0.086 \\
Short-term discipline & & & \\
Black & 0.218 & 0.170 & $-0.369^{*}$ & $-0.360^{* * *}$ \\
Hispanic & 0.152 & $0.407^{* *}$ & -0.081 & 0.046 \\
\hline
\end{tabular}

Note: $*, * *$ and $* * *$ indicate statistical significance at the $10 \%, 5 \%$ and $1 \%$ levels.

misconducts are offset by declines in suspension rates. Similarly, lower short-term disciplines for alcohol and physical altercation misconducts may be partially traded-off for higher expulsions, transfers and suspensions. These results parallel previous research, which finds that schools with a larger black student body are more likely to use extremely punitive discipline and implement zero-tolerance policies rather than first warn the students (Welch and Payne, 2010).

Table 4 presents the unconditional and conditional elasticity estimates with respect to the black student body, which provide suggestive evidence that variation in discipline rates attributable to schools' racial compositions may exist primarily in schools where inconsistent disciplinary behaviour occurs. $^{2}$ Conditional elasticity estimates indicate that in schools with inconsistent disciplinary outcomes, more severe punishments are used in response to a larger black student body. However, unconditional elasticity estimates are not statistically significant, suggesting that it may not simply be the case that least severe discipline is observed in schools with a predominantly white student body or that the toughest punishments occur in schools with a predominantly black student body. Rather, in schools where inconsistent disciplinary behaviours are observed, a proportion of the inconsistency is attributable to student demographics. This is consistent with Kinsler (2011).

\footnotetext{
${ }^{2}$ We do not present elasticity estimates with respect to the Hispanic student body because the Tobit models' marginal effect estimates indicate a weak relationship between disciplinary inconsistencies and changes in the Hispanic student population.
} 
Table 4. Discipline elasticity estimates with respect to the per cent of the black student body

\begin{tabular}{lllll}
\hline & Nonfirearm weapon & Illegal drugs & Alcohol & Physical altercations \\
\hline Expulsion/transfer & & & & \\
Unconditional elasticity & 0.021 & 0.008 & 0.013 & 0.028 \\
$\begin{array}{l}\text { Conditional elasticity } \\
\text { Suspension, }>5 \text { days }\end{array}$ & $0.001^{* *}$ & $0.001^{* *}$ & $0.001^{*}$ & $0.003^{* * *}$ \\
$\begin{array}{l}\text { Unconditional elasticity } \\
\text { Conditional elasticity }\end{array}$ & -0.038 & -0.016 & & \\
Short-term discipline & $-0.001^{* * *}$ & $-0.001^{* * *}$ & 0.013 & 0.022 \\
Unconditional elasticity & 0.011 & & & $0.001^{*}$ \\
Conditional elasticity & 0.000 & 0.011 & -0.019 & -0.023 \\
\hline
\end{tabular}

Note: $*{ }^{* *}$ and $* * *$ indicate statistical significance at the $10 \%, 5 \%$ and $1 \%$ levels.

\section{Conclusions}

While calls for greater discretionary power for evaluating student misconduct have increased, inconsistent disciplinary behaviours across schools can inequitably impact students' access to education opportunities. We show that a portion of observed disciplinary inconsistencies can be attributed to differences in the student body's racial composition and that these effects are concentrated in schools with larger black student bodies. Moreover, we find that differential disciplinary behaviour is not unconditionally related to student demographics; rather, student body racial compositions are more likely to influence disciplinary decisions in schools that already have variability in making those decisions. Consequently, public policy that seeks to reduce educational inequities must be crafted with particular attention to the complexities underlying schools' existing predispositions to disciplinary inconsistencies.

\section{Supplemental data}

Supplemental data for this article can be accessed at http://dx.doi.org/10.1080/13504851.2014.978065

\section{References}

Bernburg, J. and Krohn, M. (2003) Labeling, life chances, and adult crime: the direct and indirect effects of official intervention in adolescence on crime in early adulthood, Criminology, 41, 1287-318. doi:10.1111/j.1745-9125.2003.tb01020.x

Finn, J. (1989) Withdrawing from school, Review of Educational Research, 59, 117-42. doi:10.3102/ 00346543059002117

Fitzpatrick, M. D., Grissmer, D. and Hastedt, S. (2011) What a difference a day makes: estimating daily learning gains during kindergarten and first grade using a natural experiment, Economics of Education Review, 30, 269-79. doi:10.1016/j. econedurev.2010.09.004

Kinsler, J. (2011) Understanding the black-white school discipline gap, Economics of Education Review, 30, 1370-83.

Kinsler, J. (2013) School discipline: a source or salve for the racial achievement gap?, International Economic Review, 54, 355-83. doi:10.1111/ j.1468-2354.2012.00736.x

McDonald, J. and Moffitt, R. (1980) The uses of tobit analysis, The Review of Economics and Statistics, 62, 318-21. doi:10.2307/192 4766

Welch, K. and Payne, A. (2010) Racial threat and punitive school discipline, Social Problems, 57, 25-48. doi: 10.1525/sp.2010.57.1.25 